\title{
Antropologia Econômica e Psiquiatria: Uma Ressonância Neurodecisões no Desenvolvimento do Consumismo Compulsivo
}

\author{
Silas Santos Silva*, Adelina Cíntia S. S. do Nascimento \\ *silasssilva92@gmail.com
}

\begin{abstract}
O position paper tem como objetivo discutir as características das decisões do consumismo humano, analisado pela investigação do papel da antropologia no modelo básico da teoria econômica com ênfase em psiquiatria. A metodologia antropológica visa distinguir fatores históricos no desenvolvimento humano e seu comportamento na tomada de decisões. Assim, este trabalho foi desenvolvido por uma pesquisa bibliográfica. De acordo com os resultados na interpretação da revolução antropológica na economia é dada especial atenção à influência das tradições e crenças, que é externo à atividade econômica dos fatores responsáveis pela formação do comportamento sociais do indivíduo e da comunidade como um todo. Com base nos dados sobre o papel das externalidades internalizadas é possível especular sobre a necessidade de incluir a utilidade social e simbólica no estudo do discurso da escolha racional.
\end{abstract}

\section{JEL: B30, B41, D10, D70, D87, Z13}

\section{INTRODUÇÃO}

Apesar da grande demanda no interesse científico e leigo, sem manifestações de que o oniomania esteja aumentando em termos de predominância. As diferentes áreas como implícitas suposições do agente "indevido" específica para a antropologia, a psiquiatria e a economia a sua evolução comportamental no consumo. A explicação destes pressupostos permite classificar o grau de interdependência de trocas simbólicas e sua forma atual. Podemos reconhecer as formas institucionais e comportamentais da ação decisiva dessa relação, nos conjuntos sociais e ideológicas diferentes eram pessoais.

A economia baseia-se no fato de que cada produto tem um preço, que é definido pelo mercado. A propaganda do ponto de vista da relação de mercado é vista como chave para a equivalência de preço e custo. Relações com o mercado, agir, assim, como valores absolutos. Na medida em que o "como este" ou "aquele objeto" é percebido como um "corpo mercadoria" qualquer que seja a sua relação de troca, se torna uma troca econômica.

Há vários aspectos dessa transformação: Em primeiro lugar, todas as relações sociais corroboram para as relações econômicas, em segundo lugar, a medida da vida pública é útil, em terceiro lugar, o critério da verdade do conhecimento é eficiência e em quarto lugar, os métodos de valores coincidem com justificação das formas de avaliações [1].

No teor da afirmação acima, é fundamental admitir que alguns produtos de qualquer natureza das substâncias nos remetem a visão econômica de coisas, leva ao fato de que 
em nossos olhos rapidamente perde toda substancialidade. Como afirma Marx,

POL-éEatravés de exemplos que hábitos começam a parecer evidente que para o público a relação de produção toma a forma de coisas, ao mesmo tempo, condição para a propagação desta visão é uma revisão do produto e expressão concentrada no trabalho investido nele [2].

No contexto supracitado, o presente artigo tem como objeto de estudo a visão da antropologia e ciência econômica através de uma análise da decisão no desenvolvimento do consumismo na ótica da psiquiatria. Elenca como meta geral no estudo discutir as características das decisões do consumismo humana pela investigação do papel da antropologia no modelo básico da teoria econômica.

Diante disso, tem-se a seguinte problemática: Como se estabelece a relação de consumismo desde a antiguidade até atualidade? O interesse em abordar o tema em questão partiu do intuito de contribuir na discussão da temática no espaço educacional e cientifico; elencar a relevância de consumir somente o necessário, a fím de aniquilar a supervalorização de produtos e mercadorias, o que pode levar o indivíduo a adquirir o transtorno de compras compulsivo, levando-o a situações tenebrosas em sua vida.

O caminho trilhado nesta pesquisa tem enfoque na pesquisa bibliográfica. Logo, a função epistemológica da pesquisa e a necessidade de delimitação de uma base segura para o desenvolvimento desse processo, nesta seção será apresentado o delineamento teórico-metodológico da pesquisa em questão, onde foram consultadas várias literaturas relacionadas à antropologia e neuroeconômica [3,25], consumismo e sua interação social, que possibilitou a este artigo tomar forma para ser fundamentado na pesquisa bibliográfica, que segundo Marconi e Lakatos (1992, p. 43 e 44) este modelo de pesquisa "tem como finalidade fazer com que o pesquisador entre em contato direto com materiais escritos sobre um determinado assunto, auxiliando o cientista na análise de suas pesquisas ou na manipulação de suas informações" [4].

Em suma, este artigo discute as características que caracterizam o exemplo de tomada de decisão da troca reciprocidade do indivíduo, à troca de presentes, especificidade das relações da propriedade em um determinado contexto institucional e a natureza das obrigações de reciprocidade. Na segunda parte do artigo é dada especial atenção à consideração de controvérsia entre o formalismo e substantivíssimos dentro do discurso de recursos metodológicos da antropologia e econômica, bem como o problema comportamental da intensão de consumo, levantado e relacionado com restrições da abordagem funcional para o surgimento de instituições.

\section{MATERIAL E MÉTODOS}

A metodologia do presente estudo fundamentou-se numa pesquisa e revisão sistemática da literatura, A pesquisa bibliográfica foi realizada utilizando 4 bancos de dados (SSRN, PubMed, Scopus, e Web of Science )fundamentada em teóricos que deu origem ao tema.

\section{RESULTADOS E DISCUSSÃO}

\section{A Interação de Produtos}




\section{Psychiatry on Line Brazil}

POL+das instituições da antropologia econômica. Por um lado, a quantidade acumulada de dados sobre as diversas práticas de troca de produtos permite extensos estudos teóricos com base em características comuns das propriedades, como nas obras de Marshall David Sahlins e Karl Polanyi entre outros, a especificidade da reciprocidade oferece a oportunidade de estudar as inter-relações dos componentes econômicos, culturais e sociais no ato da economia local $[5,6,23]$.

No âmbito da antropologia econômica, as atividades econômicas não podem ser separadas de seu contexto social e religioso, pois elas são a personificação real das crenças e tradições, que, por sua vez, causar e legitimar a realidade econômica e definir a natureza do comportamento, tanto o indivíduo quanto o grupo. Assim, observações possibilitam perceber que a economia está a tornar-se uma cultura de categorias de reciprocidades "O valor de troca, representando principalmente proporção quantitativa como à proporção em que os consumidores" uns tipos de valores são trocados por valor de uso de outro tipo, a relação está constantemente a mudar em função do tempo e lugar [7].

O "sistema de categorias", o procedimento científico proposto, inerentes a ela, em primeiro lugar, é claro, o modelo das ciências naturais de sistema de conceito através do qual ele descreve a natureza, já foi apresentado na realidade social, trabalhou no ato de correntes trocas. Antes a ideia apareceu na forma de abstração pura, abstração tem trabalhado na realidade social do mercado, a mercadoria de troca envolve uma dupla abstração: abstração da natureza mutável dos bens no ato de troca e a abstração do concreto, empírico, ação sensual, a natureza privada dos bens[9]

O trabalho atividade inteiramente concentrada na fabricação e desempenho é o sujeito do conhecimento econômico só na medida das diferenças entre os ricos e os critérios para a sua avaliação, entre a lógica do açambarcamento e a especulação lógica entre o comportamento do consumidor e o valor de troca. "Ela representa um declínio do mercantilismo de William Petty, refletir sobre o que é à base do "preço natural", uma da primeira vez na análise de agendamento da relação entre a riqueza e o dinheiro governamental para a análise da proporção de produtos e os esforços para criá-las" $\mathrm{O}$ trabalho é o pai da economia e o princípio ativo da riqueza nações [10].

Smith também se conecta a riqueza e os investimentos de trabalho existente: "O custo fonte de qualquer bem para uma pessoa que os tem em mente não é usado para desfrutar dele ou pessoalmente consumir e trocá-lo para outras coisas, igual à quantidade de trabalho que ele pode comprá-lo ou obter a sua disposição". Este trabalho representa a base para mais "preço natural", e o valor de câmbio, fazendo desse um tesouro de todos os povos [10].

O resultado do trabalho como uma espécie de conceito não é apenas um ponto como centro de atenção, mais atua como uma espécie de centro. Organizar todo o desempenho econômico em geral e pré- representação da própria economia em particular. Segundo W. Petty vê o trabalho como forças do indivíduo, as forças de preparação de determinado assunto. Já Adam Smith, por sua vez, tem deliberadamente. Ela expõe o trabalho estudando, investido em qualquer nação na criação da riqueza das nações. Marx só está disposto a falar sobre "Trabalho social", seus pensamentos como o seu próprio trabalho. Temporariamente alterado a categoria de custos: Neste sentido, o custo 


\section{Psychiatry on Line Brazil}

está baseado na troca que ocorre entre indivíduos específicos (ou grupos de Pol+indivíduos), em seguida, em conexão com a troca realizada entre nações e, por fim, apenas no contexto de interesse econômico geral. Não menos importante é o deslocamento das metáforas-chave economia. Inicialmente metáfora fisiológica distribuída antes toda a riqueza que é comparada com as forças de vida, e passou acumulada, ao mesmo tempo, também, é claro, esta metáfora espalhar mais dinheiro, considerado o sangue do organismo social ou depósitos de gordura $[2,11]$.

Mais tarde eles começaram a tocá-lo de trabalho, aparece como uma pesquisa fonte das forças vitais da sociedade e, ao mesmo tempo, como o centro do sofrimento humano. Ao mesmo tempo em que era puramente alegórica, ele enfatiza a tornar-se mais literalmente. Em paralelo, ele acaba por trabalhar etapa como uma espécie de metáfora para uma variedade de dificuldades e perdas. Estas dizem respeito à transformação, de modo que os três aspectos camarada: por um lado ás forças de fixação percepção, e em segundo lugar, interpretações categóricas valor e, em terceiro lugar, as metáforas do conhecimento econômico, cada um destes três aspectos ocorre no âmbito da formação da visão da atividade laboral das ações na expressão abrangente e concentrado nas práticas sociais [12].

\section{A Economia Desde a Antiguidade aos dias Atuais.}

O termo "economia" tem dois significados: o significado formal refere-se à economia como a lógica da ação racional e tomada de decisão, como escolha racional entre os usos alternativos de meios limitados (escassos). O segundo, substantivo significado, no entanto, pressupõe nem a tomada de decisão racional nem condições de escassez. Ele simplesmente se refere ao estudo de como os seres humanos vivem em seu ambiente social e natural. Polanyi [13].

Os antropólogos abraçaram a posição substantivista como empiricamente orientada, pois não impunham pressupostos culturais ocidentais em outras sociedades onde eles poderiam não ser justificados. Quanto a este último tipo de áreas de troca da vida social não é afetados ou quase não afetados pelas relações de mercado, não pode haver questão de algo como equivalência entre valor e preço. Esta equivalência é meramente relativa, desde que a própria existência do mercado é nenhum valor ou um valor apenas o suficiente condicional $[14,15]$.

Assim como a possibilidade de valores de troca equivalentes certificado, por assim dizer, pela presença de dinheiro equivalente à possibilidade de troca de valores pareceram ser calibrados pela presença da língua. Um exemplo da possibilidade de associar palavras a dizer e a possibilidade de troca valor a antropologia estruturalista de Lévi-Strauss faz a pergunta: "Não parece impulso original". Ele encoraja as pessoas a "trocar palavras, imagens fantasma decorrente, por sua vez, devido ao desempenho do simbólico funcionar desde a sua criação", "e ele mesmo responde-lhe:" Como apenas o facto de que o som é percebido como imediatamente os valores propostos para o altofalante e o ouvinte, era torna-se controversa, que pode neutralizar só através da troca de valores mutuamente complementares [16].

Com relação "o corpo de comércio" do assunto torna-se apenas todas as não mercadorias, todo mundo faz não correlacionada com a mercadoria. Assim, qualquer ação reduz a troca sorrindo para a troca simbólica. Esta redução inclui vários aspectos: 


\section{Psychiatry on Line Brazil}

POL+ASRelações, e em segundo lugar, o princípio básico da existência social. Ele inclui diversos tipos de presentes e envolve todo um sistema de rigorosas respostas presentes das regulamentados (na verdade representando mais ou menos sofisticada extorsão) [17].

A troca de mercadorias é uma troca de alienáveis objetos entre as pessoas que estão em estado de recíproca independência que estabelece uma quantitativa relação entre os objetos trocados... A troca de presentes é uma troca de inalienáveis objetos entre as pessoas que estão em estado de recíproca dependência que estabelece uma qualitativa relação entre os negociantes [18].

Coisa que concedeu está à espreita na substancialidade cativeiro. A troca de presentes ou, em outras palavras, a troca de presentes é destinado a garantir que incansavelmente confirmar tal substancialidade a fim de atestar coisas na sua substância e simultaneamente detectar a substância. Natureza não mercantil desta troca de presentes (troca de presentes) ré- queres análise, longe da economia política das coisas visão em que um tipo de relações económicas coágulo produção. Tal análise e oferecem antropólogos, em termos de questões de reconhecimento mútuo dos Estados nossa sociedade entre si, envolvendo consolidação do seu desenvolvimento social papéis, delimitação de funções executáveis - subordinação [22].

Do ponto de vista das ciências sociais, um presente de troca não é apenas um recurso econômico. O principal objetivo dessa comunicação - estabelecer ou reafirmar as redes sociais de indivíduos ou grupos. "No entanto, se a seguinte ideia Marx sorrindo no tipo de sociedade de organização da economia", assume a forma de coisas, formar a substância é totalmente dependente da natureza dos aspectos simbólicos estrutura social, de tudo o que é baseada em realização de rituais, normas e regulamentos, cujo valor é ainda mais simbólico, menos do que essas regras são regras "Escritura", menor a regras são dadas a ampla publicidade e quanto menos se transforma esses rituais codificados [2].

No entanto, agora "produtos que "fala bem, e justificar, qualquer produto propriedades tive do material são eleitos concretização benéfico"“. Dentro utilitário intercâmbio econômico permeia todas as relações sociais relações com os empregados e os seus princípios gerais é cheio de conteúdo da ação, abordagens para se tornar perfeito, mas informal, ao mesmo tempo introduz aleatoriedade no processo público de desenvolvimento como um tipo de condições necessárias. Como parte da mesma simetria, a trocar toda a volta: o utilitário não é amplamente distribuído princípio e permeia as relações econômicas e sociais [20.21].

Vamos voltar à questão da interpenetração de real primeiro no âmbito das atividades de codificação. Esta interpenetração desde que o preço de um tipo de dissolução - mas agora não é o preço dissolução do simbólico no real, como no caso da prática de trabalho, - Preço e dissolução simbólica real (que também leva a misturando os dois conceitos). Atividade simbólica - relacionada doação e descascamento - ficam em antropologia dupla interpretada - definido. Por um lado, é uma atividade associada com a expressão códigos que o impressionas, ursos e, mais importante, no literal sentido da palavra usa. Por outro lado, é qualquer atividade, confiando em estrita subordinação da estrutura e sua abordagem cuidadoso conteúdo. (Tal ambiguidade de interpretação 


\section{Psychiatry on Line Brazil}

sobre a dualidade o próprio conceito de regras, bem como os conceitos de Pol+ć́digo ou estrutura). Pergunta Trégua é semelhante para determinar se as regras explícitas - explicitamente.

\section{Comportamentos Psiquiátricos}

A influência social é um fator especialmente relevante no consumo compulsivo, conscientemente padrões escolhidos, pelo contrário, estão relacionados com as normas, implícita e inconsciente executável o problema não é do consumo mais a relação nas quais as pessoas se relacionam com consumo [19,24].

Embora o prazer e a excitação sejam geralmente associados ao ato de compra, é comum para os consumidores considera dos compulsivos a manifestação de que costumam sentir pequena alegria ou utilidade com o bem comprado. Há casos até em que o comprador tem medo de que alguém, como o cônjuge, descubra o seu ato e, assim, esconde o bem comprado e nunca o usa. Para esses autores, o medo de ser descoberto (a) e o fato de gastar mais do que o orçamento permite geram culpa e ansiedade no comprador compulsivo e esses sintomas permite auxiliar na identificação das diferenças entre os consumidores compulsivos e os não compulsivos[25].

Uma definição para o comportamento compulsivo pode ser, então, apresentada: "Uma resposta a um estímulo incontrolável ou desejo de obter, usar ou experimentar um sentimento, uma substância ou uma atividade que leva um indivíduo a engajar repetidamente em um comportamento que irá causar danos ao indivíduo e/ou outros" (O’ Guinn e Faber, 1989, p.147) [26]. Essa definição é amplamente discutida na literatura de comportamento do consumidor [27,28,29,30,31,32]. Exemplos desse comportamento incluem compulsão por jogos, compras, bebidas alcoólicas, trabalho e comida. Uma distinção é feita entre o consumo compulsivo e o impulsivo. $\mathrm{O}$ compulsivo geralmente ocorre durante estados emocionais negativos (tensão, ansiedade, tristeza) e ajuda a fornecer um alívio para esses sentimentos. Já o comportamento impulsivo ocorre geralmente durante estados emocionais positivos [33].

\section{CONCLUSÃO}

É constante o crescimento de pesquisas acadêmicas sobre o consumo compulsivo, haja vista que é antropologicamente historicizado nas áreas da economia e da psiquiatria. Logo que o mercado lança proposta através das redes de comunicação, ou seja, as propagandas, que influência psicologicamente os consumidores e principalmente os compradores compulsivos por produtos, marcas, "promoções", moda, entre outros, além desses compradores, temos também a alienação com trocas de presentes, através de uma ideologia e mercadológica da reciprocidade em dar e receber, reduzindo simbolicamente as relações sociais e a existência social.

Nesse contexto os consumidores compulsivos estão inseridos na relação simbólica, além de adquirirem objetos e produtos sem necessidade, são impulsionados psicologicamente a comprar, o que agrava sua vida econômica, pois muitas das vezes sem condições financeiras adquirem mercadorias e não conseguem pagar. Levando- os a 


\section{Psychiatry on Line Brazil}

POL+Enfín, a tomada de decisão do indivíduo o posiciona dentro da sociedade.

\section{5. REFERÊNCIAS BIBLIOGRÁFICAS}

[ 1 ] Marx K. A contribution to the critique of political economy. InMarx Today 2010 (pp. 91-94). Palgrave Macmillan, New York. DOI: 10.1057/9780230117457_5

[2] Elardo JA. Marx, Marxists, and economic anthropology. Review of Radical Political Economics. 2007 Sep;39(3):416-22.DOI: 10.1177/0486613407305292

[ 3 ] GLIMCHER ,Paul W.; FEHR, Ernst; CAMERER ,Colin ; POLDRACK ,Russell Alan, Neuroeconomics: Decision Making and the Brain,2008 , Academic Press

[4] Marconi MD, Lakatos EM. Metodologia do trabalho científico. São Paulo: Atlas. 2001;6.

[ 5 ] Polanyi K. The economy as instituted process. Trade and market in the early empires. 1957;243.

[ 6 ] SAHLINS, Marshall. A Primeira Sociedade de Afluência, in: CARVALHO, E. (Organizador), Antropologia Econômica, Ed. Ciências Humanas, 1978:6-43

[ 7 ] SAHLINS, Marshall. Culture and practical reason. Chicago: The University of Chicago Press, 1976.

[ 8 ] .MARX, K. O capital: crítica da economia política. 25. ed. Rio de Janeiro: Civilização Brasileira, 2008. (Livro I, v. 1)

[9] GUDEMAN, Stephen. The Anthropology of Economy. Blackwell Publishers, Malden, Massachusetts, 2001

[ 10 ] SMITH, Adam .Wealth of nations. University of Chicago Bookstore.2005

[ 11 ] Aspromourgos, T. On the origins of classical economics: distribution and value from William Petty to Adam Smith. Routledge.2013.

[ 12 ] SAHLINS, Marshall. Cosmologias do Capitalismo: o setor transpacífico do sistema mundial, in: Religião e Sociedade 1992.

[ 13 ] Polanyi-Levitt, K. Karl Polanyi as socialist. Humanity, Society, and Commitment: On Karl Polani (Montreal: Black Rose, 1994), 115, 134

[ 14 ] DUMONT, Louis. Introduction à deux theories d'anthropologie sociale. Paris: Mouton, 1971

[15] Taussig Michael The genesis of capitalism amongst a South American peasantry: devil's labor and the baptism of money. Comparative studies in society and history. 1977 Apr;19(2):130-55. DOI:10.1017/S0010417500008586

[ 16 ] Lévi-Strauss C. La notion de structure en ethnologie. Anthropologie structurale. 1958:303-50.

[ 17] MALINOWSKI, Bronislaw. Malinowski on the Kula. In: LeCLAIR Jr., E.; SCHNEIDER, H. K. (Ed.). Economic anthropology: readings in theory and analysis. New York: Holt, Rinehart and Winston Inc., 1968. p. 17-39.

[ 18 ] GREGORY, Chris . Gifts and Commodities. Londres: Academic Press.1982 Pp. 100-101.

[19] SILVA SANTOS, Silas.(2016) Neuroeconomia e suas Interfaces com a Psiquiatria - Saúde Mental: Personalidade consumista uma patologia emocional? Prazer ou Necessidade? Psychiatry Online Brazil,Vol.21, n06,pp 616-3. Disponível em: < http://www.polbr.med.br/ano16/art0616-3.php >. Acesso em Nov. de 2016

[ 20 ] POLANYI, Karl. A Grande Transformação. Ed. Campus, Rio de Janeiro, 2000 (1944).

[ 21 ] POLANYI, Karl, ARENSBERG, Conrad, PEARSON, Harry.Trade and Market in the Early Empires. The Free Press, New York, 1957

[22 ] PETTY, William e Graunt, J. (1899). The Economic Writings of Sir William Petty (Vol. 1). University Press 


\section{Psychiatry on Line Brazil}

[23] DAVID SAHLINS, Marshall. Stone Age Economics. Chicago: Aldine 1972. POL+BF Disponível em: https://libcom. org/files/Sahlins\%20-\%20Stone\%20Age\%20Economics. Pdf. Acesso em Nov. de 2016.

[ 24 ] D'astous, A., Maltais, J., \& Roberge, C. (1990). Compulsive buying ten-dencies of adolescent consumers. Advances in Consumer Research, 17,306-312.

[25] Faber, R. J., O'guinn, C. T., \& Krych, R. (1987). Compulsive Consumption. pp.125-132. Advances in Consumer Research (14).

[ 26] Faber, R. J., \& O'guinn, C. T. (1989). Classifying Compulsive Consumers:Advances in the Development of a Diagnostic Tool. pp. 738-744. Advancesin Consumer Research (16) Provo, UT: Association for Consumer Research

[27 ] Cole, L., \& Sherrell, D. (1995). Comparing scales to measure compulsive buying:an exploration of their dimensionality. Advances in Consumer Research, $22,419-427$.

[ 28 ] Hassay, D. N., \& Smith, M. C. (1996). Compulsive buying: An examination ofthe consumption motive. Psychology \& Marketing, 13(8), 741-752.

[29] Hirschman, E. C. (1992). The Consciousness of Addiction: Toward a GeneralTheory of Compulsive Consumption. Journal of Consumer Research, 19,155179.

[ 30 ] Magee, A. (1994). Compulsive Buying Tendency as a Predictor of Attitudes andPerceptions. Advances in Consumer Research, 21, 590-594.

[ 31 ] Rindfleisch, A., Burroughs, J. E., \& Denton, F. (1997). Family structure, materialism and compulsive consumption. Journal of Consumer Research, 23(4),312-325.

[ 32 ] Shoham, A., \& Brencic, M. M. (2003). Compulsive buying behavior. Journal ofConsumer Marketing, 20(2/3), 127-138.

[33 ] Hirschman, E. C., \& Stern, B. B. (1999). The Roles of Emotion in ConsumerResearch. pp. 4-11. Advances in Consumer Research (26). 